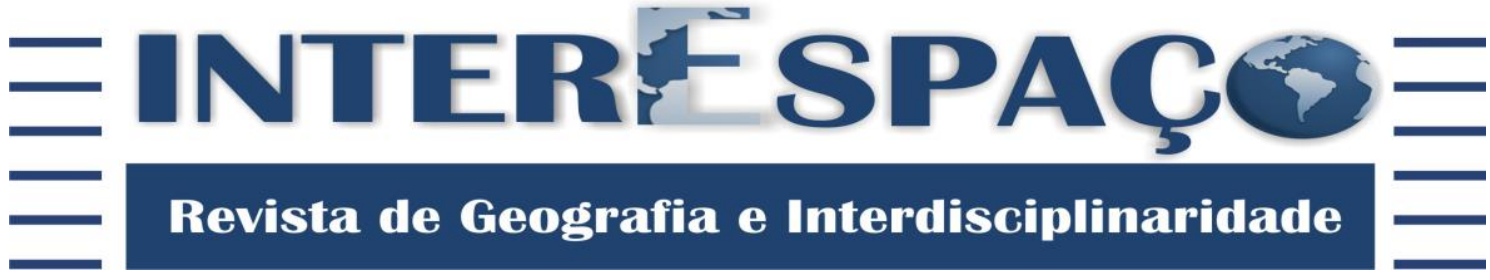

\section{RECONFIGURAÇÕES SOCIOESPACIAIS E SOCIOPOLÍTICAS EM TEMPOS DE CIBERCULTURA: uma nova cultura política?}

\author{
SOCIAL-SPATIAL AND SOCIO-POLITCAL RECONFIGURATIONS IN \\ TIMES OF CYBERCULTURE: a new political culture?
}

\section{CONFIGURACIONES SOCIALESPACIALES Y SOCIOPOLÍTICAS EN TIEMPOS DE CIBERCULTURA: una nueva cultura política?}

\begin{abstract}
Doutorando em Desenvolvimento Social e Mestre em Geografia pela Universidade Estadual de Montes Claros - UNIMONTES. Docente das Faculdades Integradas Pitágoras de Montes Claros -

FIPMoc.

gustavo.ccpv@gmail.com

\section{Hiago Felippe Carvalho Chaves}

Graduando em Comunicação Social - Publicidade e Propaganda pelas Faculdades Integradas Pitágoras de Montes Claros - FIPMoc. Bolsista de Iniciação Científica - PROIC/FIPMoc.
\end{abstract}

Gustavo Souza Santos hiagoc07@gmail.com

\section{Maria das Graças Campolina Cunha}

Doutora em Geografia pela Universidade Federal de Uberlândia - UFU. Docente do

Departamento de Geociências da Universidade Estadual de Montes Claros - UNIMONTES. gracapira@yahoo.com.br

Recebido para avaliação em 05/06/2017; Aceito para publicação em 07/03/2018.

\section{RESUMO}

O ciberespaço despontou como um lócus espaço-temporal, fazendo emergir uma nova ágora: eletrônica, digital, virtual, povoada pela multiplicidade de sujeitos inscritos na malha virtual, os quais não partem de nenhuma circunscrição geográfica limítrofe, mas aparelhada com o turbilhão de informações dispensadas nesse meio fluido e hipermidiático. Tal cenário tem sido marcado por eventos e fenômenos de base política e engajamento social na última década, gerando questionamentos que tocam a expressão popular, o poder técnico e o poder político. E mais, subvertendo o espaço e gestando novas dinâmicas socioespaciais. O objetivo deste estudo foi discutir as reconfigurações socioespaciais e sociopolíticas promovidas pelas práticas sociais em tempos de cibercultura. Reflete-se à luz da literatura pertinente (Pierre Lévy, Milton Santos, Henri Lefebvre, Harvey e outros), o fenômeno ciberativista desdobrado nos últimos anos: os intentos do WikiLeaks em 2006, a Primavera Árabe de meados de 2010, o Occupy Wall Street de 2011 e as manifestações de junho de 2013 no Brasil. Nesse panorama, não apenas reconfigurações sociopolíticas são observadas, mas também socioespaciais. Desvela-se diante dos olhos uma tríade de repercussões: a ampliação e o resgate da consciência de mundo, participativa e social dos sujeitos; a maturação de uma nova cultura política ante a contemporaneidade da informação e da tecnologia, e, a progressão de uma revolução tecnocultural a suscitar novas práticas socioculturais.

Palavras-chave: Cibercultura; Ciberespaço; Espaço; Poder; Política.

\section{ABSTRACT}


| Reconfigurações socioespaciais e sociopolíticas em tempos de cibercultura: uma nova cultura política? |

| Gustavo Souza Santos | Hiago Felippe Carvalho Chaves | Maria das Graças Campolina Cunha|

Cyberspace has emerged as a locus space-time, giving rise to a new agora: electronic, digital, virtual, populated by the multiplicity of subjects enrolled in the virtual network, which does not leave any borderline geographical jurisdiction, but equipped with the whirlwind of exempt information in this fluid and hypermiditic medium. Such a scenario has been marked by events and phenomena of political base and social engagement in the last decade, generating questions that touch popular expression, technical power and political power. And more, subverting the space and generating new socio-spatial dynamics. The objective of this study was to discuss socio-spatial and sociopolitical reconfigurations promoted by social practices in times of cyberculture. It is reflected in the light of the relevant literature (Pierre Lévy, Milton Santos, Henri Lefebvre, Harvey and others), the phenomenon cyberactivist unfolded in recent years: the WikiLeaks attempts in 2006, the Arab Spring mid-2010, the Occupy Wall Street demonstrations in 2011 and June 2013 in Brazil. In this panorama, not only socio-political reconfigurations are observed, but also socio-spatial ones. A triad of repercussions is unveiled before the eyes: the amplification and the rescue of the participant and social world consciousness of the subjects; the maturation of a new political culture before the contemporaneousness of information and technology, and the progression of a technocultural revolution to stimulate new socio-cultural practices.

Keywords: Cyberculture; Ciberspace; Space; Power; Politics.

\section{RESUMEN}

El ciberespacio surgió como un locus espacio-temporal, haciendo emerger una nueva ágora: electrónica, digital, virtual, poblada por la multiplicidad de sujetos inscritos en la red virtual, los cuales no parten de ninguna circunscripción geográfica limítrofe, sino aparte con el torbellino de informaciones dispensadas en ese medio fluido e hipermidiático. Tal escenario ha sido marcado por eventos y fenómenos de base política y compromiso social en la última década, generando cuestionamientos que tocan la expresión popular, el poder técnico y el poder político. Y más, subvirtiendo el espacio y gestando nuevas dinámicas socioespaciales. El objetivo de este estudio fue discutir las reconfiguraciones socioespaciales y sociopolíticas promovidas por las prácticas sociales en tiempos de cibercultura. El fenómeno ciberativista desdoblado en los últimos años, se refleja a la luz de la literatura pertinente (Pierre Lévy, Milton Santos, Henri Lefebvre, Harvey y otros), los intentos de WikiLeaks en 2006, la Primavera Árabe de mediados de 2010, el Occupy Wall Street de 2011 y las manifestaciones de junio de 2013 en Brasil. En este panorama, no sólo se observan reconfiguraciones sociopolíticas, sino también socioespaciales. Se desvela ante los ojos una tríada de repercusiones: la ampliación y el rescate de la conciencia de mundo, participativa y social de los sujetos; la maduración de una nueva cultura política ante la contemporaneidad de la información y la tecnología y la progresión de una revolución tecnológica a suscitar nuevas prácticas socioculturales.

Palabras clave: Cibercultura; Ciberespacio; Espacio; El Poder; Política.

\section{INTRODUÇÃO}

Quando Pierre Lévy afirmou que o ciberespaço é o lugar onde o mundo funciona hoje (LÉVY, 2000), talvez a sentença parecesse um aforismo de impacto para discutir um novo panorama técnico, informacional e cultural. Todavia, o dito levyniano em ressonância às suas demais discussões em torno da temática do ciberespaço e da cibercultura - e unida a outras vozes na literatura -, se tornou mais do que um ditame, mas um certame que aponta cenários e baliza novas construções. 
| Reconfigurações socioespaciais e sociopolíticas em tempos de cibercultura: uma nova cultura política?|

| Gustavo Souza Santos | Hiago Felippe Carvalho Chaves | Maria das Graças Campolina Cunha |

O ciberespaço despontou como um lócus espaço-temporal (SANTOS; TRINDADE; ROCHA, 2015) de devires e, nesse cenário de pervasividade tecnológica e superabundância de acesso à informação, uma nova ágora emerge. Uma ágora eletrônica, digital, virtual, povoada pela multiplicidade de sujeitos inscritos na malha virtual, os quais não partem de nenhuma circunscrição geográfica limítrofe e é aparelhada com o turbilhão de informações dispensadas nesse meio fluido e hipermidiático.

Ora, a ágora é o espaço onde o discurso ressoa e gera construções e coletividades. É o espaço que ecoa entre os matizes do particular para o público, espacializados em uma dimensão de pertença, de ação e tônica altamente socializante e politizante. Eis o que os tempos de cibercultura têm oferecido como tenro fruto: a produção de uma ágora digital povoada por sujeitos em trânsito e sob o forte influxo informacional contemporâneo.

A rigor, a ágora e seu pulso socializante/politizante é cooperativa, sensível à realidade e pronta para incursões transformadoras à realidade. E não é diferente na ágora digital onde a densidade tecnocultural vigente e a vazão da informação em constante atualização desenvolveram forte senso de empoderamento e uma inclinação à participação social.

Esse impulso empoderador catalizado pelos cenários da cibercultura desabrochou na ampliação da consciência de mundo cidadã, gerando produtos e gestos sociopolíticos particularmente novos. A exemplificação para isso está no fenômeno ciberativista desdobrado nos últimos anos. Desde os intentos da Primavera Árabe de meados de 2010, no Occupy W all Street de 2011, até as manifestações brasileiras de junho de 2013, um novo desenho sociopolítico tem se firmado com base em uma revolução de natureza comunicacional.

Movimentos, discursos, pautas, reinvidicações e ativismos tomaram o mundo de modo admirável. Mídia, imprensa, modelos de governança e lideranças se viram sob um teto de questionamentos sobre o que tais fenômenos querem dizer sobre os tempos hodiernos e que significados estão sendo esculpidos na história e na sociedade (CASTELLS, 2013).

Governos depostos, reorganizações políticas, tomadas de decisões, segredos de interesse público revelados e uma série de resultados que cooperam para um armamento do cidadão, para que a democracia seja plenamente vivida e o sentido do político seja resgatado numa premissa que se arvora simplesmente em promover o bem-estar social por meio do desmantelamento de estruturas de opressão. 
| Reconfigurações socioespaciais e sociopolíticas em tempos de cibercultura: uma nova cultura política? |

| Gustavo Souza Santos | Hiago Felippe Carvalho Chaves | Maria das Graças Campolina Cunha |

Nesse panorama, não apenas reconfigurações sociopolíticas são observadas, mas também socioespaciais. A operação on-line dos movimentos e seus desdobramentos não anulam a operação off-line, acompanhada de um novo sentido de apropriação do espaço público, das ruas, do território e do espaço vivido.

Assim, resta indagar: como as práticas sociais na cibercultura têm empoderado os sujeitos, reconfigurado a participação política? Nesse sentido, propõe-se aqui, à luz desse cenário, refletir as reconfigurações socioespaciais e sociopolíticas promovidas pelas práticas sociais em tempos de cibercultura, discutindo suas perspectivas e se há a formação de uma nova cultura política.

\section{TEMPOS DE CIBERCULTURA: reconfigurações sociopolíticas e socioespaciais}

No pleno gozo do advento das tecnologias da informação e comunicação, o fragor da técnica passou a permear o ordenamento social. Do personal computer ao smartphone, é possível enxergar novos paradigmas de processamento da comunicação e da atividade humana, não se prendendo apenas à realidade das TICs ou das telecomunicações.

Uma multiplicidade de lógicas, linguagens, capacidades e dispositivos povoaram não apenas o espaço social, mas seu imaginário. Derivam daí o frenesi das redes sociais, os códigos próprios e hipertextuais da internet e toda a sorte de figuras socioculturais que fertilizam o dia a dia e que mesmo relegados a um julgamento depreciativo, revelam riquezas mais abissais sobre a contemporaneidade.

Os eixos de funcionamento da sociedade, da economia, da comunicação e da política se reordenaram ante uma aura tecnológica agregadora, facilitadora e pervasiva. Os fluxos produtivos são aparelhados, as atividades ordinárias são automatizadas e o progresso técnico passa a ser uma máxima de desenvolvimento, sinônimo de avanço e símbolo de êxito.

Em uma plena floresta de dispositivos e tecnologias, a informação tornou-se um viço social contemporâneo. Ela mune, integra, amplia e potencializa. $\mathrm{Na}$ internet, a informação é veloz e avassaladora em termos de difusão. Assim, o animal social aristotélico torna-se ainda mais cadente onde informação e comunicação são propulsores que alteram as dinâmicas preexistentes de ordenamento social.

A quotidianidade passou a incorporar novas tessituras, agora advindas de uma (i)materialidade virtualizante e deflagradora de novas interfaces cotidianas: socialização, identidade, ativismos e inteligência coletiva. Os tempos de cibercultura anunciam assim 
| Reconfigurações socioespaciais e sociopolíticas em tempos de cibercultura: uma nova cultura política?|

| Gustavo Souza Santos | Hiago Felippe Carvalho Chaves | Maria das Graças Campolina Cunha |

mais do que uma inocente e situacional revolução técnico-científica, mas sinalizam reconfigurações significativas na vida social, pública e privada.

\section{Reconfigurações socioespaciais: novos lócus para novas performances}

É possível explanar que, a partir de sua emergência, o ciberespaço despontou como um novo lócus espaço-temporal (SANTOS; TRINDADE; ROCHA, 2015). Tal asserção implica que as perspectivas abarcadas por esse novo meio não se desdobraram apenas em um plano técnico, informacional e estruturante. Prerrogativas espaciais foram ressignificadas a partir das interfaces, relações telemáticas e fluxos informacionais proporcionados no/pelo ciberespaço.

É elucidativo refletir que o ciberespaço possui uma constituição material e lógica, baseada nas redes de telecomunicações e interconexões telemáticas que suportam suas operações e relações entre aparatos, dispositivos e sujeitos. Ao mesmo tempo, integram sua constituição as operações virtuais, as linguagens, as relações e as práticas codificadas e decodificadas contínua e diariamente.

Isso implica num prospecto onde o ciberespaço e as práticas que dele emergem - a cibercultura - possuem uma espacialidade particular, ancorada em operações materiais e imateriais, ou virtuais. Suas bases, relações e práticas se estruturam, ao mesmo tempo, em um plano on-line - conectado, telemático, telepresencial, virtual - e off-line - posto na materialidade sensível.

A dinâmica espacial do ciberespaço, bem como as práticas nele/dele derivadas, promovem, assim, uma reconfiguração socioespacial. Da reflectância on-line e off-line e da virtualidade, pendem novas formas de espacializar a realidade e suas relações, gerando novas práticas, novos sentidos e novas interfaces homem-espaço e homem-sociedade.

O cotidiano também é virtual. Práticas comunicacionais e informacionais são deflagadoras de uma rede volumosa de fluxos. As perspectivas de Castells (2007) com o espaço de fluxos e a sociedade em rede assumem aqui uma importante chave de compreensão de como o ciberespaço enunciado por Lévy (2000) se imiscui da vida cotidiana e (i)material na contemporaneidade.

Em Lévy (2000), a cibercultura possui três pulsões fundamentais e articuladoras, esclarecedoras dessas reconfigurações socioespaciais aqui em questão, geradoras de novos devires e novas performances: interconexão, comunidades virtuais e inteligência coletiva. Tais pulsões adicionaram às práticas sociais novos significados e acepções. 
| Reconfigurações socioespaciais e sociopolíticas em tempos de cibercultura: uma nova cultura política?|

| Gustavo Souza Santos | Hiago Felippe Carvalho Chaves | Maria das Graças Campolina Cunha |

A interconexão, como primeira pulsão, diz da integração de equipamentos, vias lógicas, redes de conexões telemáticas, computadores e dispositivos em uma malha intercomunicante. Todavia, esse processo de integração de infraestrutura e comunicação lógica se expande também nos sujeitos que trafegam nessas vias abertas, produzindo uma interconexão de sujeitos e suas relações também.

Posto que há uma integração massiva de sujeitos e dispositivos em uma lógica de interconexão, um sentido socializante e mediado é possível, originando constructos de sociabilidade, as comunidades virtuais. Pessoas em rede se unem e se associam por afinidades, projetos comuns e sentidos de pertença desenvolvidos em seu tráfego.

Tal agremiação socializante e interconectada compartilha relações e tais relações dimensionam práticas colaborativas. Isto é, saberes, conhecimentos, informações e dados são partilhados, difundidos e produzidos em rede em um viço de melhoramento contínuo da própria rede e das relações nela desenvolvidas, numa espécie de solidariedade em rede, ou na acepção levyniana, inteligência coletiva.

As três pulsões radicadas na interconexão de dispositivos e pessoas, na formação de núcleos de sociabilidade e na produção e compartilhamento de informações em rede formam o corolário da cibercultura e demonstram as condições para que relações e práticas sociais e espaciais sejam reconfiguradas nesse panorama.

Com um lócus de sociabilidade, interconexão e compartilhamento informacional, o espaço e as relações nele desenvolvidas ganham novos contornos. O fluxo veloz da conexão e o modelo das relações produzem um novo modelo de acesso e socialização da informação, desencadeando novos esquemas de sociabilidade e de espacialidade de tais práticas. Integram-se aqui gestos e atos que se concretizam virtual e materialmente, ou seja, tem procedência on-line e off-line.

As pulsões da cibercultura postuladas por Lévy (2000) associadas às variáveis de socialização, interação e velocidade da informação e dos produtos gerados a partir dela promovem um cenário de novas práticas sociais e, consequentemente espaciais. A sociabilidade produzida pela interconexão gera práticas que espacialmente se constroem em um plano (i)material, radicando-se no espaço material, como no espaço virtualizado.

Lefebvre (1991) desenvolveu o conceito de práticas espaciais como performances no espaço que abarcam o cotidiano e a representação espacial em meio de símbolos, vivências e imagens. Diante dos cenários virtualizantes e da subversão (i)material do ciberespaço e da cibercultura, tais práticas espaciais se veem embebidas em uma nova dinâmica: difusa, pervasiva e reticulada. 
| Reconfigurações socioespaciais e sociopolíticas em tempos de cibercultura: uma nova cultura política?|

| Gustavo Souza Santos | Hiago Felippe Carvalho Chaves | Maria das Graças Campolina Cunha |

Nos tempos de cibercultura, as práticas espacias ganham um novo ritmo. Isto é, não são apenas espacializadas, mas imersas em sociabilidade e, consolidando-se como socioespaciais, passam a impulsionar e subsidiar novas espacialidades, territorialidades, escalas e enredamentos.

Manifestações difusas como a Primavera Árabe no solo africano e no Oriente Médio, movimentos na Grécia, o Occupy Wall Street norte-americano e insurgências sulamericanas como as manifestações de junho de 2013 no Brasil, são vetores de práticas e performances socioespaciais em tempos de cibercultura.

O desenho de cada movimentação carregou escopos e motivações próprias, em ressonância na construção de projetos de país em harmonia com projetos de vida de seus povos. Além disso, em contingência, tais movimentos traduziram novas acepções de expressões geográficas, portanto, reconfigurações espaciais.

Territorialidades de insurgência se levantaram robustecidas por ativismos de reflectância on-line e off-line, espacializando reivindicações e vozes de modo reticulado, com inclinações multi e transescalares. Novos constructos socioespaciais são erigidos na medida em que versatilidade virtual e a fluidez da cibercultura permitem novos devires para novos lócus revolucionados entre espaço e sociedade.

Em tempos de cibercultura e de pleno gozo e avanço das TICs, as formas de processamento espacial e a própria produção do espaço são reconfiguradas em uma perspectiva (i)material e virtualizante, gerando novas tessituras e enredos. Isso não significa a anulação do espaço, mas uma nova combinação de fatores e densidades a produzi-lo, recombiná-lo e defini-lo.

O espaço que na definição de Santos (2004) é um conjunto indissociável, solidário e contraditório de sistemas de objetos e ações onde a história se dá, passa a se combinar com as redes, definidas em Castells (2007) como camadas espaciais de difusão, comunicação, transmissão e inter-relação de fluxos. Essa combinação origina espaços reticulados, isto é, um espaço encadeado, neural e perpassado pela performance de rede.

Produz-se, portanto, espaços, espacialidades e socialidades reconfiguradas em sua tessitura, forma e dinâmica, permitindo novas formas e novas modalidades de práticas espaciais e performances socioespaciais. Confessam essa prerrogativa as relações cotidianas e os movimentos como a Primavera Árabe, o Occupy Wall Street e as manifestações brasileiras de 2013. Movimentos espacializados e reconfigurados pela camada advinda dos tempos de cibercultura. 
| Reconfigurações socioespaciais e sociopolíticas em tempos de cibercultura: uma nova cultura política?|

| Gustavo Souza Santos | Hiago Felippe Carvalho Chaves | Maria das Graças Campolina Cunha |

Operam nessa reconfiguração socioespacial variáveis que complexificam e enriquecem a dinâmica da análise socioespacial. A velocidade dos fluxos, a alta interatividade da informação produzida e compartilhada, a multiplicidade linguística, a profusão imagética, a diversidade de relações entre coletividades e identidades.

\section{Reconfigurações sociopolíticas: uma nova cultura política?}

Espaço, suas práticas e relações reconfiguradas, novas tessituras e dinâmicas produzidas. Postas as reflexões sobre transformações de produção e trato socioespacial em tempos de cibercultura, é preciso lançar algumas luzes sobre as performances que, se arrolando a esses cenários, têm se desdobrado.

No cenário confessional da Primavera Árabe, Occupy Wall Street e outros (HARVEY et al., 2012), bem como junho de 2013, além das operações socioespaciais características entre espacialidades, territorialidades, escalas e redes, desdobraram-se pulsos de expressão sociopolítica.

A comunicação, no aporte do poder simbólico, é historicamente uma indumentária política que dimensionam relações de poder - e de contrapoder, conforme Castells (2013). Tendo por base os eventos de insurgência em questão, tal perspectiva se agenciou por meio de conclames e informações compartilhadas na internet, por meio de redes sociais e outros produtos.

Para compreender esse aspecto, um retorno ao enunciado da ágora. O ideário democrático grego da ágora é recuperado de maneira particular no ciberespaço, em tempos de cibercultura. As pulsões socializantes e engajadoras em um espaço cativo para a construção de projetos de governabilidade e participação social ganhou contornos vertiginosos.

A ágora agora é eletrônica, digital, virtual (VELLOSO, 2008). Tendo o substrato oferecido pelo ciberespaço, ancorado nas pulsões da interconexão, do sentido comunitário virtual e da inteligência coletiva, os sujeitos desempenham papéis e produzem sentidos de expressão sociopolítica.

Os fluxos informacionais altamente compartilhados e compartilháveis se atrelam aos sujeitos em um enredamento que não conhece circunscrições fronteiriças ou limítrofes. Sendo a ágora o espaço onde as vozes ressonam gerando construções coletivas, no ciberespaço, a ágora digital tem acústica garantida. 
| Reconfigurações socioespaciais e sociopolíticas em tempos de cibercultura: uma nova cultura política? |

| Gustavo Souza Santos | Hiago Felippe Carvalho Chaves | Maria das Graças Campolina Cunha|

$\mathrm{Na}$ ágora digital, o sentido de pertença, a ação e a tônica socializante e politizante são importantes marcadores. Na cibercultura, a ágora que é uma espacialidade marcadamente cooperativa e sensível à realidade, ganha pulso na densidade tecnocultura, fluida, difusa, veloz e comunicante, gerando um senso de empoderamento e participação social particulares.

Se na organização social comum, algumas vozes não têm condições suficientes de ecoarem eficientemente, na agremiação virtual, é possível produzir ressonâncias com outras vozes que na ágora digital se coordenam. Tal estado feito impulso empoderador, nos arranjos da cibercultura, promoveu novas formas de expressão sociopolítica e novas consciências.

Movimentos de insurgência passaram a incorporar insumos nas TICs para gestar novas formas de manifestação, de participação social, de luta por direitos, de reivindicações e outras práticas. Protagonismo, ação, resistência, engajamento, solidariedade são agora perpetrados por formatos sociopolíticos que se processam nessa ágora digital, aparelhados pelas TICs, aditivados na cibercultura, reconfigurados.

Emerge assim o conceito de ciberativismo. Práticas insurgentes e socializadas localizadas e espargidas a partir do ciberespaço, sem prescindir da conjuntura fora dele, na perspectiva de Alcântara (2015). Um rebento do ciberespaço e da cibercultura que, a exemplo das primaveras e ocupações em todo o mundo (HARVEY et al., 2012; CASTELLS, 2013), tem promovido resistências, vocalizado indignações e nutrido novas esperanças em torno de projetos de vida e país.

O ciberativismo possui em sua essência um caráter renovado de contrapoder. Os ativismos dele dispensados, operam do ciberespaço e se processam reticulados, isto é, em fluxos de ação, redes de engajamento. Tais redes se organizam na perspectiva de redes submersas, veladas ao grande público e ao circuito midiático e, cadenciadas por laboratórios culturais por meio de diretórios e núcleos diversos, desvelam significados e se tornam visíveis na eclosão de atos de ativismo (SOUZA, 2013).

$\mathrm{Na}$ cibercultura, novas formas de sociabilidade se desenvolveram (SANTOS et al., 2014). As identidades também se imiscuíram desse novo cenário e, no tocante aos ativismos, assumem a alcunha de identidades de projeto, onde os sujeitos lançam mão de novos artefatos culturais e redefinem sua identidade tendo em vista a transformação da estrutura social, delimitando projetos e protagonismos (CASTELLS, 2008).

Ora, de posse de dispositivos, linguagens e insumos do universo on-line e interconectado, os sujeitos remodelam suas identidades, dispensando novos projetos de 
| Reconfigurações socioespaciais e sociopolíticas em tempos de cibercultura: uma nova cultura política?|

| Gustavo Souza Santos | Hiago Felippe Carvalho Chaves | Maria das Graças Campolina Cunha |

ação, resistência e transformação (PEREIRA, 2013). Dão sabor a isto, os exemplos assumidos desde 2011 (HARVEY et al., 2012). Entre identidades e projetos, reconfigurações sociopolíticas, assim como socioespaciais, são sentidas, percebidas, visualizadas e desencadeadas.

Tecnologia, comunicação e informação produzem nessa perspectiva a insurgência de cenários de contrapoder e redes de organização social com vistas à manutenção da sociedade, da nação, dos lares (ALCÂNTARA; D’ANDRÉA, 2014). Desvela-se diante dos olhos uma tríade de repercussões: a ampliação e o resgate da consciência de mundo, participativa e social dos sujeitos; a maturação de uma nova cultura política ante a contemporaneidade da informação e da tecnologia, e, a progressão de uma revolução tecnocultural a suscitar novas práticas socioculturais (LEMOS, 2015).

Postas a dimensão do ciberespaço e da cibercultura e as reconfigurações socioespaciais promovidas entre novas práticas, processos e cenários, é possível destacar que os sujeitos impulsionados por essa nova matriz de interconexão e sociabilidade, encontraram meios e subsídios para construção de identidades de projeto, ampliando sua consciência de mundo.

Mais do que a ampliação de uma consciência panorâmica da realidade, um resgate a consciências adormecidas, amortizadas ou suprimidas ao longo do tempo. Importa que, ativada e resgatada tal consciência, ela se transforme em memória. Memória redentora, que contempla a história, revisita expectativas e experiências passadas e reelabora um itinerário identitário de ação (BRANDÃO, 1998).

Essa memória redentora é ao mesmo tempo resposta, estímulo e ação. Entre o espaço da experiência e o horizonte de expectativas do passado e sua disrupção nos esboços contemporâneos da realidade social, a memória cria uma consciência renovada do tempo (HABERMAS, 1990; BRANDÃO, 1998). Tal consciência - anamnética -, suportada por eixos identitários de projeto (CASTELLS, 2008), elucida caminhos de ação, de busca pela redenção do passado não realizado, gestando novas indumentárias de engajamento.

Conscientes, os sujeitos começam a se organizar e a desenvolver papéis diversos de protesto, manifestação e intervenção (CARNEIRO, 2012). Diante dos insumos produzidos pela informação, comunicação e tecnologia, os sujeitos passam a desencadear novas relações com a política e sua cultura. Assim, culturas políticas podem estar sendo resgatadas, despertadas, renovadas ou maturadas.

Para esta discussão, os tempos de cibercultura que reconfiguraram as relações entre espaço, política e sociedade, maturaram uma nova abordagem de cultura política, pautada 
| Reconfigurações socioespaciais e sociopolíticas em tempos de cibercultura: uma nova cultura política?|

| Gustavo Souza Santos | Hiago Felippe Carvalho Chaves | Maria das Graças Campolina Cunha|

nesse espectro que concatena informação, comunicação e contemporaneidade. Sejam resgatadas ou renovadas, as culturas políticas convergem para um novo paradigma de vivência amparado pelas práticas da cibercultura.

Contempla-se a progressão de uma revolução tecnocultural suscitando novas práticas socioculturais, desde reconfigurações socioespaciais à reconfigurações sociopolíticas (SANTOS et al., 2015). Esse desenvolvimento delineia novas linguagens, hábitos, formas de ação, processos e eventos, acrescentando novas camadas aos desdobramentos sociopolíticos e as formas de engajamento e participação social.

Espaços, territórios, redes, escalas e lugares convivem com o dado virtual. Poder, contrapoder, ativismo e participação social se relacionando com o status digital. Novos significados vão sendo incorporados à cotidianidade e, gestando a seu tempo, novos lócus, dispositivos e corpus socializantes e politizantes. De reconfigurações, surgem funcionalidades renovadas e atualizadas, protegendo em sua essência novos sentidos que podem eclodir a qualquer momento em novos organismos e histórias.

Uma nova cultura política? Bem, novas abordagens de vivência e compressão da participação sociopolítica sob a fecundidade de práticas, processos e linguagens da cibercultura, entre informação, interação e comunicação. O pensamento democrático e para além dele tem sido repensado nos últimos tempos, para não esgotar sua discussão, é preciso lançar foco e atenção sobre os significados em desenvolvimento dessas reconfigurações (LEMOS; LÉVY, 2010; LÉVY, 2002).

\section{CONSIDERAÇÕES FINAIS}

Ciberespaço e cibercultura alteraram as dinâmicas sociais pela subversão da materialidade, da concepção da realidade e da ação cotidiana. Para além de um fenômeno técnico, tal cenário operou reconfigurações socioespaciais e sociopolíticas. Os sujeitos têm um espaço rizomático, reticulado e fluido para desenvolverem práticas e performances sob a marca da velocidade, da interação e da conexão.

Em tempos de cibercultura, diante de novos eixos de processamento da percepção e da prática sociopolítica, novos constructos e processos podem ser desencadeados. Desde a consciência individual à agremiação participativa, desde as mudanças submersas do cotidiano até os eventos-fenômeno. Há, numa malha socializante e politizante, uma revolução tecnocultural em ocorrência. E nela, a gênese e a renovação de novas práticas e performances espaciais, sociais, culturais e políticas. 
| Reconfigurações socioespaciais e sociopolíticas em tempos de cibercultura: uma nova cultura política?|

| Gustavo Souza Santos | Hiago Felippe Carvalho Chaves | Maria das Graças Campolina Cunha |

Se o ciberespaço é o lugar onde o mundo funciona hoje, como esta discussão é aberta, isso se dá por uma série de transformações que tecnologia, informação e comunicação têm operacionalizado no ordenamento social e no pensamento humano, produzindo novos lócus e novos devires. Há que se ajustar e manter foco sobre tais transformações, seus significados e suas incursões na sociedade e nos sujeitos.

\section{REFERÊNCIAS}

ALCÂNTARA, L. M. Ciberativismo e movimentos sociais: mapeando discussões. Aurora: Revista de Arte, Mídia e Política, São Paulo, v. 8, n. 23, p. 73-97, jun./set. 2015.

ALCÂNTARA, L. M.; D’ANDRÉA, C. F. B. Redes de movimentos sociais e intervenção na esfera pública interconectada: um estudo da campanha pelo limite da terra na internet (2012). In: SILVEIRA, S. A.; BRAGA, S.; PENTEADO, C. (Org.). Cultura, política e ativismo nas redes digitais. São Paulo: Fundação Perseu Abramo, 2014. p. 23-37.

BRANDÃO, C. R. A primeira. Walter Benjamin. A dívida solidária com o passado. In: Memória Sertão: cenários, cenas, pessoas e gestos nos sertões de João Guimarães Rosa e de Manuelzão. São Paulo: Cone Sul; Uberaba: Editora Uniube, 1998. p. 27-34.

CARNEIRO, H. S. Rebeliões e ocupações de 2011. In: HARVEY, D. et al. Occupy. Movimentos de protesto que tomaram as ruas. Tradução de João Alexandre Peschanski et al. São Paulo: Boitempo/Carta Maior, 2012. p. 7-14.

CASTELLS, M. A sociedade em rede. 11 ed. São Paulo: Paz e Terra, 2007.

. O poder da identidade. Tradução de Klauss Brandini Gerhardt. 6. ed. São Paulo: Editora Paz e Terra, 2008.

Redes de indignação e esperança. Movimentos sociais na era da internet. São Paulo: Zahar Editora, 2013.

HABERMAS, J. O discurso filosófico da modernidade. Lisboa: Dom Quixote, 1990.

HARVEY, D. et al. Occupy. Movimentos de protesto que tomaram as ruas. Tradução de João Alexandre Peschanski et al. São Paulo: Boitempo/Carta Maior, 2012.

LEFEBVRE, H. The Production of Space. Tradução de D. Nicholson-Smith. Oxford: Basil Blackwell, 1991.

LEMOS, A. Cibercultura: tecnologia e vida social na cultura contemporânea. 7. ed. São Paulo: Editora Sulina, 2015.

LEMOS, A.; LÉVY, P. O futuro da internet. Em direção a uma ciberdemocracia planetária. São Paulo: Paulus, 2010.

LÉVY, P. Cibercultura. São Paulo: Editora 34, 2000. 
| Reconfigurações socioespaciais e sociopolíticas em tempos de cibercultura: uma nova cultura política?|

| Gustavo Souza Santos | Hiago Felippe Carvalho Chaves | Maria das Graças Campolina Cunha |

Ciberdemocracia. São Paulo: Instituto Piaget, 2002.

PEREIRA, J. M. Brasil, meu Brasil brasileiro: entre o sonambulismo e o despertar do gigante. Revista Pensata, Guarulhos, v. 3, n. 1, nov. 2013.

SANTOS, G. S.; FREITAS, R. F.; REIS, V. M. C. P.; ROCHA, J. S. B. Cibercultura e contemporaneidade: panoramas de uma sociedade da comunicação. Aurora: Revista de Arte, Mídia e Política, São Paulo, v. 7, n. 20, p. 83-97, jul./set 2014.

SANTOS, G. S.; SAMPAIO, C. A.; REIS, V. M. C. P.; ROCHA, J. S. B. Cibercultura, interações sociais e pós-modernidade: realidade versus virtualidade. Espacios, Caracas, v. 36, n. 22, dez. 2015.

SANTOS, G. S.; TRINDADE, L. T.; ROCHA, J. S. B. Um novo lócus espaço-temporal: considerações sobre a dinâmica espacial e temporal do ciberespaço. Animus: Revista Interamericana de Comunicação Midiática, Santa Maria, v. 14, n. 28, jul./dez. 2015.

SANTOS, M. A Natureza do Espaço: técnica e tempo, razão e emoção. 4. ed. São Paulo: Edusp, 2004.

SILVA, C. A.; TANCMAN, M. A Dimensão Socioespacial do Ciberespaço: uma nota. GEOgraphia, Niterói, v. 1, n. 2, p. 55-66, 1999.

SILVEIRA, S. A. Para analisar o poder tecnológico como poder político. In: SILVEIRA, S. A.; BRAGA, S.; PENTEADO, C. (Org.). Cultura, política e ativismo nas redes digitais. São Paulo: Fundação Perseu Abramo, 2014. p. 33-48.

SOUZA, M. L. Os conceitos fundamentais da pesquisa sócio-espacial. Rio de Janeiro: Bertrand Brasil, 2013.

VELLOSO, R. V. O ciberespaço como ágora eletrônica na sociedade contemporânea. Ciência da Informação, Brasília, v. 37, n. 2, p. 103-109, maio/ago. 2008. 